Mémoire.

\title{
HOMOGENEITY OF SPERM STRUCTURE IN SIX SPECIES OF SCHISTOSOMES (DIGENEA, PLATYHELMINTHES)
}

\author{
J.-L. JUSTINE *. B. G. M. JAMIESON **, V. R. SOUTHGATE ***
}

SUMMARY

Sperm ultrastructure is described in six species of schistosomes: Schistosoma curassoni, S. rodhaini, S. intercalatum, S. bovis, $S$. margrebowiei, and $S$. mansoni. Sperm structure in the schisto- somes is homogeneous, but very different from that of other Digenea.

RÉSUmÉ : Homogénéité de la structure des spermatozoïdes chez six espèces de Schistosomes (Digenea, Plathelminthes).

L'ultrastructure du spermatozoïde est décrite chez six espèces de schistosomes: Schistosoma curassoni, S. rodhaini, S. intercalatum, S. bovis, S. margrebowiei, and S. mansoni. La structure du spermatozoïde est homogène chez les schistosomes, mais très différente de celle des autres Digenea.
Schistosomes are highly aberrant digeneans (Combes, 1991). The spermatozoa of schistosomes have been shown to be exceptional in the Digenea in having a single axoneme (two in other Digenea) which extends as a free flagellum (incorporated in others); in possessing a single diffuse central structure in the $9+《 1 »$ axoneme (instead of the highly structured central element otherwise constant for the $9+\ll 1 »$ axonemes of the Digenea and other Trepaxonemata); in the short conical (rather than filiform) condition of the nucleus and sperm body; location of discrete mitochondria anterior to the nucleus (rather than filiform, fused and parallel to it); retention of a striated root (rather than loss during spermiogenesis); and retention of a centriole consisting of nine triplets (rather than two centrioles with nine doublets or singlets).

These characteristics of schistosome sperm were listed by Justine $(1985,1991$ c). They have been described, in whole or in part, for Schistosoma mansoni (see Spence and Silk, 1971; Kitajima, Paraense and Correa, 1976; Otubanjo, 1980, 1981; Justine and Mattei, 1981; Irie, Basch and Basch, 1983); S. bovis (see Justine, 1980, 1982; Justine and Mattei, 1981); S. haematobium (see Erasmus,

* Laboratoire de Biologie Parasitaire, Protistologie, Helminthologie, URA 114 CNRS, Muséum National d'Histoire Naturelle, 61, rue Buffon, 75231 Paris Cedex 05, France.

** Zoology Department, University of Queensland, Brisbane 4072, Australia.

*** Department of Zoology, Natural History Museum, Cromwell Road, South Kensington, London SW7 5BD, England.

Reprints: J.-L. Justine, address as above.

Accepté le : 2 avril 1993.
1987); S. margrebowiei (see Awad and Probert, 1989). However, it is desirable to establish the extent of variability in schistosomes with regard to these features of sperm morphology by re-examining and extending these observations.

We here investigate the ultrastructure of sperm of $S$. curassoni (from sheep, Dakar, Senegal), S. rodhaini (isolated from wild caught snails, Biomphalaria sudanica, Bujumbura, Burundi) and S. intercalatum (isolated from wild caught snails, Bulinus forskalii, Franceville, Gabon) which have not previously been studied, and re-examine those of $S$. bovis (from cattle, Tambacounda, Senegal), S. margrebowiei (from lechwe, Kobus leche, Lochinvar National Park, Zambia) and S. mansoni (isolated from wild caught snails, Biomphalaria spp., Medinha, Saudi Arabia).

Triplet centrioles are confirmed for S. bovis (Fig. In, p) and S. margrebowiei (Fig. Im). All other features of schistosome sperm listed above are constant for the investigated species (Fig. Ia-q).

Homogeneity and peculiarity of schistosome sperm relative to those of other Digenea is thus confirmed. The adaptive and ontogenetic origins of this exceptional sperm structure are problematic. Kitajima et al. (1976) have related the "rudimentary" form of the sperm of S. mansoni (which superficially resembles that of so-called « primitive » invertebrate sperm) to the claim that « sperm seem to be continuously poured, instead of periodically ejaculated; through a pore just behind the ventral sucker ». We can find no evidence that sperm are shed freely into the gynaecophoric canal. Justine $(1985,1991 c)$ has interpreted the suite of peculiar characters of schistosome sperm which we have confirmed above as representing a progenetic deve- 


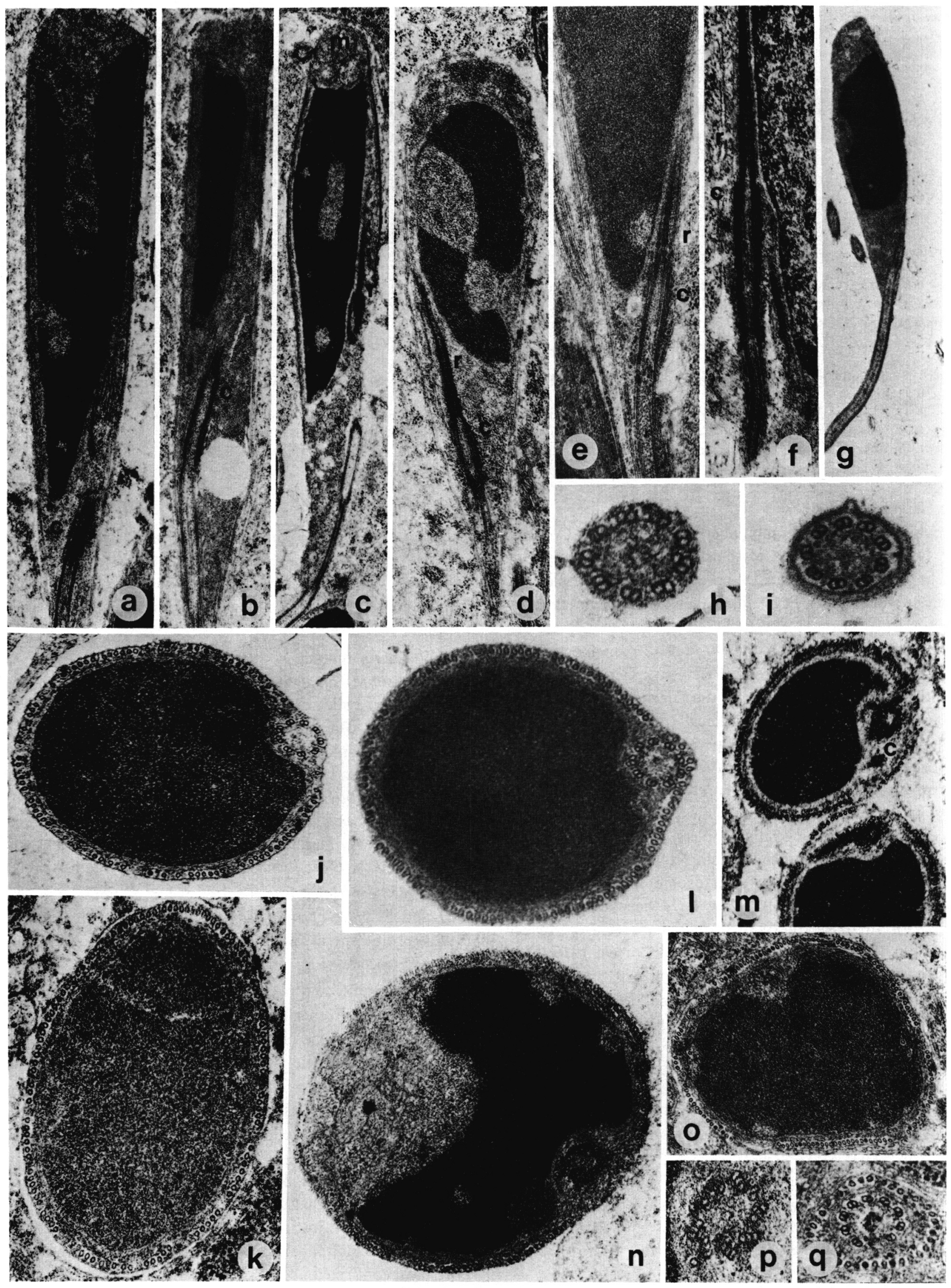


FIG. 1 : a-d and g. - Longitudinal section of mature sperm bodies in testis (a-d) and seminal vesicle (g); $a, b, S$. rodhaini, $\times 19500$; c, $S$. margrebowiei, $\times 13000 ; d$, S. curassoni, $\times 19500 ; g$, S. bovis, $\times 13000$. Fig 1 : e-f. - Basal part of axoneme in mature sperm (e) and spermatid $(f)$, with associated rootlet; $e, S$. curassoni, $\times 26000 ; f$, S. margrebowiei, $\times 26000$. Fig. 1 : h-i. - Transverse sections of $9+$ " 1 " (but non trepaxonematan) flagella in mature sperm; note absence of dynein arms; $h, S$. rodhaini, $\times 100000$; $i$, S. bovis, $\times 80$ 000. Fig. $1:$ j-o. - Transverse sections of mature sperm bodies. $j, S$. mansoni, $\times 40000 ; k, S$. intercalatum, $\times 40000 ; l$, $S$. bovis, $\times 52000 ; m$, section with centriole, $S$. margrebowiei, $\times 30000 ; n$, section with centriole, $S$. bovis, $\times 39000 ;$ $o$, S. curassoni, $\times 30000$. Fig. 1 : p-q. - Transverse sections of basal part of sperm body. p, centriole, $S$. bovis, $\times 75000 ; q$, base of axoneme and encircling microtubules, S. curassoni, $\times 52000 . c$, centriole; $m$, mitochondria; $r$, striated root.

lopment of the spermatid, the adaptive function of which remains unknown. In this respect, however, it is noteworthy that only three cases of aberrant sperm structure are known in the parasitic platyhelminthes (beyond the considerable variation which occurs around a common theme, a filiform biflagellate pattern, see Justine, 1991a, b): the monogean Diplozoon, in which the two members of a pair are permanently fused and have confluent genital ducts; didymozoid digeneans, which live in encysted pairs (data in Justine, 1991a, and references therein); and schistosomes, in which the female is held in the gynaecophoric canal of the male.

\section{REFERENCES}

Awad A. H. H., Probert A. J. : Transmission and scanning electron microscopy of the male reproductive system of Schistosoma margrebowiei Le Roux, 1933. J. Helminthol., 1989, 63, 197-205.

Combes C. : The schistosome scandal. Acta Oecol., 1991, 12, 165-173.

Erasmus D. A. : The adult schistosome: structure and reproductive biology. In: The biology of schistosomes, from genes to latrines, Rollinson D., Simpson A. J. G. (Eds). Academic Press, London, 1987, pp. 51-82.

Irie Y., Basch P. F., Basch N. : Reproductive ultrastructure of adult Schistosoma mansoni grown in vitro. J. Parasitol., 1983, 69, 559-566.

Justine J.-L. : Étude ultrastructurale de la gamétogenèse de Schistosoma bovis Sonsino, 1876 (Trematoda: Schistosomatidae). Thèse de $3^{\mathrm{e}}$ Cycle, University of Montpellier, 1980, France.
Justine J.-L. : Étude ultrastructurale de la spermiogenèse des Schistosomes (Trematoda: Schistosomatidae). Afr. Med., 1982, 21, 287-292.

Justine J.-L. : Étude ultrastructurale comparée de la spermiogenèse des Digènes et des Monogènes (Plathelminthes). Relations entre la morphologie du spermatozoïde, la biologie de la fécondation et la phylogénie. Thèse d'État, University of Montpellier, 1985, France.

Justine J.-L. : Phylogeny of parasitic Platyhelminthes: a critical study of synapomorphies proposed on the basis of the ultrastructure of spermiogenesis and spermatozoa. Can. J. Zool., 1991a, 69, 1421-1440.

Justine J.-L. : Cladistic study in the Monogenea (Platyhelminthes), based upon a parsimony analysis of spermiogenetic and spermatozoal ultrastructural characters. Int. J. Parasitol., 1991b, $21,821-838$

Justine J.-L. : The spermatozoa of the schistosomes and the concept of progenetic spermiogenesis. In: Baccetti B. (ed.) Comparative Spermatology 20 Years after. Raven Press, New York, 1991c, pp. 977-979.

Justine J.-L., Mattei X. : Étude ultrastructurale du flagelle spermatique des Schistosomes (Trematoda: Digenea). J. Ultrastruct. Res., 1981, 76, 89-95.

Kitajima E. W., Paraense W. L., Correa L. R. : The fine structure of Schistosoma mansoni sperm. J. Parasitol., 1976, 62, 215-221.

Otubanjo O. O. : Schistosoma mansoni: the ultrastructure of the ducts of the male reproductive system. Parasitology, 1980, 81, 565-571.

Otubanjo O. O. Schistosoma mansoni : Astiban-induced damage to tegument and the male reproductive system. Exp. Parasitol., 1981, 52, 161-170.

Spence I. M., Silk M. H. : Ultrastructural studies of the blood fluke - Schistosoma mansoni. V. The female reproductive system - a preliminary report. S. Afr. J. Med. Sci., 1981, $36,41-50$. 